\title{
Traditional gender roles attitude and romantic partner conflict among males:
}

\author{
A Correlational study
}

\author{
*Swagata Chattopadhyay *
}

*Sujata Saha*

\begin{abstract}
:
Social norms and roles can affect our interpersonal behavior and relationships. The strain to comply with such norms, for individuals who are much less aligned with existing gender norms and roles, can create further difficulties. This paper analyzes conflicts between romantic partners in relation to traditional gender roles attitude, especially for males, in the age group of eighteen to twenty-five which roughly aligns with young adulthood. Chances of having a romantic relationship are especially high during these years. Conventional gender roles can make it more difficult for individuals to align their personality traits with societal expectations, live true to their personal socio-sexual preferences, and decide their conduct in relationships. Conventional norms and roles of masculinity and femininity can both help or hurt a relationship. Gender roles attitude here refers to the beliefs held by individuals towards any specific gender as measured by the Gender Role Attitude Scale (GRAS), developed by Prof. Dr. Simge Zeyneloölu. Another scale used was the Romantic partner conflict scale (RPCS) which refers to the everyday conflicts faced by individuals in relationships and how they handle the conflict, introduced by Tammy L. Zacchill. Here, a statistical analysis, specifically the Pearson Correlation coefficients, between GRAS and subscales of RPCS is presented.
\end{abstract}

Keywords: Gender roles, romantic relationship, relationship conflict, gender role attitude

\section{Introduction:}

A gender role, also known as a sex role, is a societal role with a range of behaviors that are considered acceptable or desirable for a person based on that person's biological sex. Gender roles are primarily focused on masculinity and femininity, although there are exceptions and variations. Gender roles affect a huge range of human conduct, often along with the apparel a person chooses, the profession a person pursues, and the personal relationships someone enters.

There are four basic kinds of gender role beliefs/attitudes: 
a. Personality traits - For example, women are often expected to be accommodating and emotional, while men are usually expected to be self-confident and aggressive.

b. Domestic behaviors - For example, some people expect that women will take care of the children, cook, and clean the home, while men take care of finances, work on the car, and do the home repairs.

c. Occupations - For example, some people are quick to assume that teachers and nurses are women and that pilots, doctors, and engineers are men.

d. Physical appearance - For example, women are expected to be thin and graceful, while men are expected to be tall and muscular. Men and women are also expected to dress and groom in ways that are stereotypical to their gender (men wearing pants and short hairstyles, women wearing dresses and make-up.

A romantic relationship is termed as a voluntarily committed relationship between two individuals who are willing to be with each other for a long term. A relationship conflict is termed as disagreement, argument, and fight within two individuals in a relationship for some reason. Relationship conflicts occur in all relationships because two people can't view all things from the same perspective. Although romantic partners tend to be quite similar in terms of age, education level, values and beliefs, and even physical attractiveness, they are nonetheless different people and these differences are bound to emerge and require negotiation. There are many different types of conflicts in relationships. Some of the most common ones include:

a. Finances - Money is one of the top reasons for conflict in relationships.

b. Personal Intimacy - when the sexual needs of one partner differ from those of the other, it might give rise to relationship conflict.

c. Insecurity - one partner seems to feel insecure about their relationship and their significance to the other partner. Insecurity can also lead to accusations of infidelity.

d. Lack of Effective Communication - lesser communication in relationships has the potential of creating an atmosphere of persistent underlying conflict.

e. Some conflate conflict with aggressiveness, expecting hurtful words, explosions of anger, or tears, and recoiling in the face of such intensity. 
f. Others believe that conflict is a sign that the relationship is fundamentally flawed and are quick to suggest breaking it off when conflict emerges. This escalation diverts attention from the issue at hand, ensuring that it remains unresolved, and shifts the conversation from a smaller issue to a much grander one.

g. Many get overcome by anxiety at the mere thought of voicing dissent or negative emotions to their partner, and as a result, stifle themselves and let their grievances go unaddressed. Avoidance is a self-defeating strategy because it ensures that the conflict never gets solved.

\section{Review of Literature}

O'Neil et al. 's $(1986,1995)$ in their thesis, studied that men's gender role conflict has negative consequences on the lives of other people. One study reported that adult sons' estimates of their fathers' gender role conflict related to their levels of gender role conflict, as well as to lower levels of attachment to their fathers (DeFranc \& Mahalik, 2002).

Studies examining the relationship between intimacy and gender role conflict in both collegeaged (Sharpe \& Heppner, 1991) and middle-aged men (Cournoyer \& Mahalik, 1995; Mahalik, Locke, Theodore, Cournoyer, \& Lloyd, 2001; Sharpe, Heppner, \& Dixon, 1995) consistently report that men with higher levels of gender role conflict express greater difficulty with intimacy. This relationship seems to be particularly salient for men with difficulty expressing their emotions in relationships (Sharpe et al., 1995) and for middle-aged men (Mahalik et al., 2001).

Kearney, Rochlen, and King (2004) reported that men who were more tolerant of sexual harassment behaviors (i.e., less likely to perceive harassing behaviors as unacceptable) expressed high levels of Success, Power, and Competition, and overall gender role conflict. This finding is consistent with several studies reporting that men's traditional gender roles contribute to problematic interactions with women.

Similar patterns emerge when relationship and marital satisfaction were examined, with men exhibiting higher levels of gender role conflict appearing to have more conflictual and less satisfying relationships and marriages. For example, Campbell and Snow (1992) found that 
married men with difficulty expressing their emotions and conflict between their work and home relations reported lower levels of relationship satisfaction.

\section{Methodology}

\section{Objectives: The objectives of this relational study are as follows:}

1. To study the relationship between gender role attitude and compromise

2. To study the relationship between gender role attitude and avoidance

3. To study the relationship between gender role attitude and interactional reactivity

4. To study the relationship between gender role attitude and separation

5. To study the relationship between gender role attitude and domination

6. To study the relationship between gender role attitude and submission

\section{Hypothesis: The hypotheses of the relational study are as follows:}

1. There is no significant relationship between gender role attitude and compromise

2. There is no significant relationship between gender role attitude and avoidance

3. there is no significant relationship between gender role attitude and interactional reactivity

4. There is no significant relationship between gender role attitude and separation

5. There is no significant relationship between gender role attitude and domination

6. There is no significant relationship between gender role attitude and submission

\section{Variables used in the present study:}

- Gender role attitude - to the beliefs held by individuals towards any specific gender as measured by the Gender Role Attitude Scale (GRAS).

- Romantic partner conflict: refers to the everyday conflicts faced by individuals in relationships and how they handle the conflict.

\section{Samples}

a. Sample size- 150

b. Sampling method - Convenience Sampling Method

c. Inclusion criteria: 
-male subjects within the age range of 18-25 in Karnataka

-who are in a relationship for at least 1 year or more (for conflicts to arise, a minimum period of 6-12 months is needed)

d. Exclusion criteria:

-subjects below 18 and above 25 years of age

-those who are not currently in a relationship

- those who are not residing in Karnataka

\section{Tools for Data Collection:}

a. Gender Role Attitude Scale (GRAS) - The instrument was developed by Prof. Dr. Simge Zeyneloölu to determine attitudes towards gender roles. It has 38 items with a 5-point Likerttype scale for each time.

Scoring: The egalitarian attitude sentences regarding gender roles were scored as 5 points for 'completely agree,' 4 points for 'agree,' 3 points for 'undecided,' 2 points for 'disagree,' and 1 point for 'disagree.' The traditional attitude sentences regarding gender roles were scored opposite to the positive sentences. The highest possible score from the scale was 190 and the lowest was 38 according to this scoring scale. The higher scores from the scale indicated that the students had more egalitarian attitudes towards gender roles and the lower scores showed that the students' attitudes were more traditional. The total score will be used for the study instead of the dimensional score.

Psychometric properties: Cronbach alpha reliability coefficient and Pearson's Product Moment Correlation Coefficient were used to measure the reliability of the GRAS. Kaiser-Meyer-Olkin (KMO) Measure of Sampling Adequacy was used for the construct validity of the GRAS to test whether the data obtained was homogeneous. The value of 0.819 was obtained as the result of the test shows that the internal consistency was good.

b. Romantic Partner Conflict Scale (RPCS) -The scale was introduced by Tammy L. Zacchilli. The Romantic Partner Conflict Scale includes 39 items with six subscales: Compromise, Avoidance, Interactional Reactivity, Separation, Domination, and Submission. The purpose of this scale is to measure conflict experienced by individuals in romantic relationships.

Scoring: The following items were under the mentioned factors: Compromise: Items 1-14; Avoidance: Items 15-17; Interactional Reactivity: Items 18-23; Separation: Items 24- 28; 
Domination: Items 29-34; Submission: Items 35-39. The scoring of all items will be done on a 04 Likert scale, the least score being 39 and the highest possible score being 156. A higher score on the scale indicates higher conflicts in the individual's relationship and a lower score indicates lower conflicts in the individual's relationship.

Psychometric properties: Test-retest correlations for the scales were as follows: Compromise (.82), Avoidance (.70), Interactional Reactivity (.85), Separation (.76), Domination (.85), and Submission (.72). These test-retest correlations are at appropriate levels (i.e., .70 or above).

Procedure for Data Collection- The participants were given a questionnaire in the form of google forms. The data was collected in a google form through the online method. Details of the participants were collected as well. The confidentiality of the participants was maintained.

Data Analysis method- Pearson product-moment correlation was done with the help of SPSS software.

\section{Ethical Considerations -}

a. The participants will be made aware of the research, their purpose, and their role in it, and with their consent, data will be collected.

b. The researcher will maintain confidentiality concerning names and results obtained from the participants.

c. Participants will be informed that the data collected, and information provided would be used strictly for academic purposes only.

d. They will have the right to withdraw from the study at any stage if they wish to do so.

\section{Results and Discussions}

The GRAS has 38 items and five subscales. The total score was used for the study instead of the dimensional score, whereas, RPCS has 39 items with six subscales of compromise, avoidance, interactional reactivity, separation, and domination. Pearson correlation was computed, on a sample of 100, between the total score obtained from the gender role attitude scale and the scores obtained from the domains of the romantic partner scale (namely: compromise, avoidance, separation, internal reactivity, submission, and domination). Upon collection of data on Google 
forms, the data was transferred to an excel data sheet which was then copied onto SPSS and the results were obtained which have been discussed in the next few sections of this chapter.

Checking normality of dataset: The histogram frequency of the GRAS and the six subscales of RPCS are analyzed and fitted with a normal curve using IBM-SPSS software. These have been presented below:
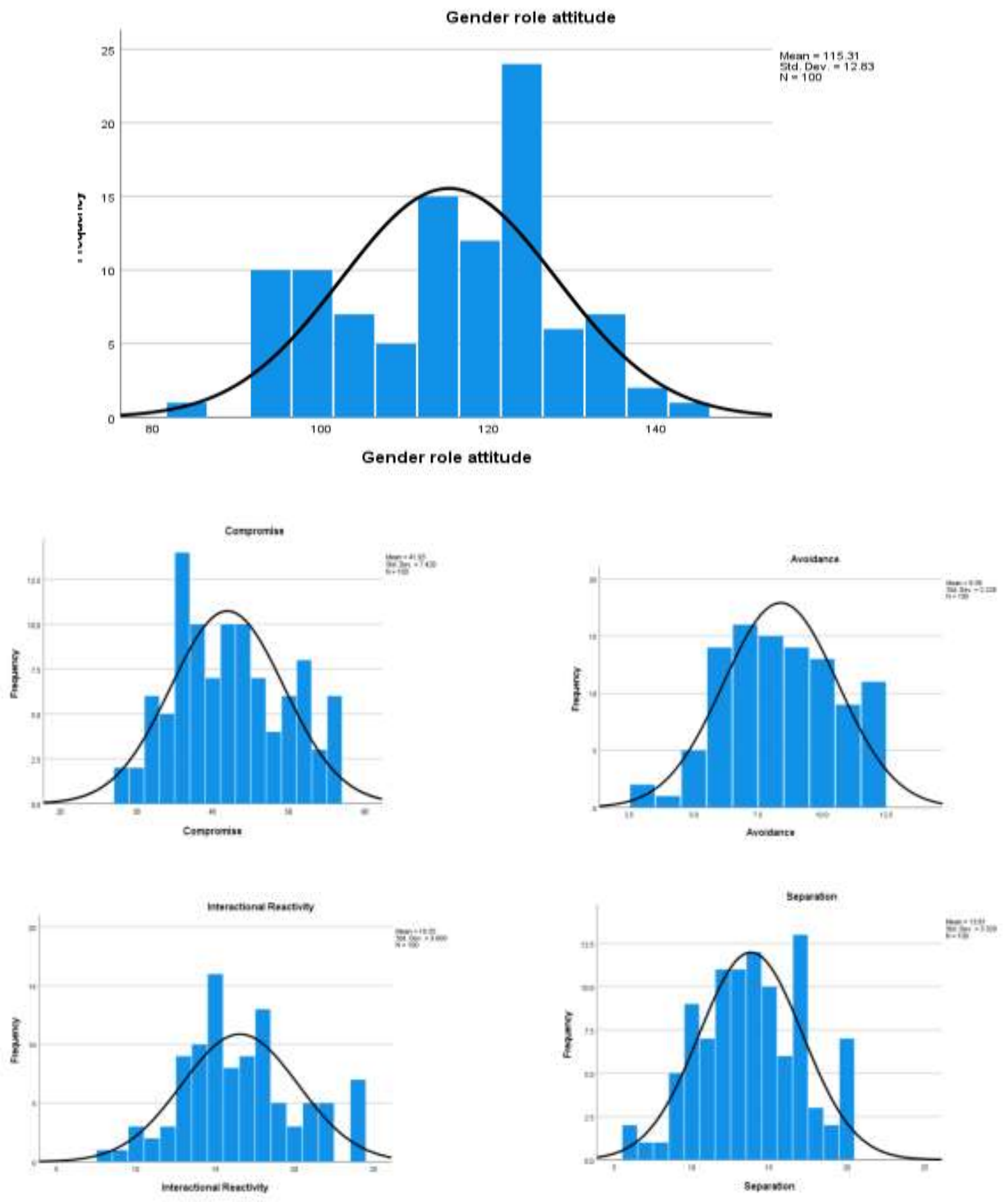

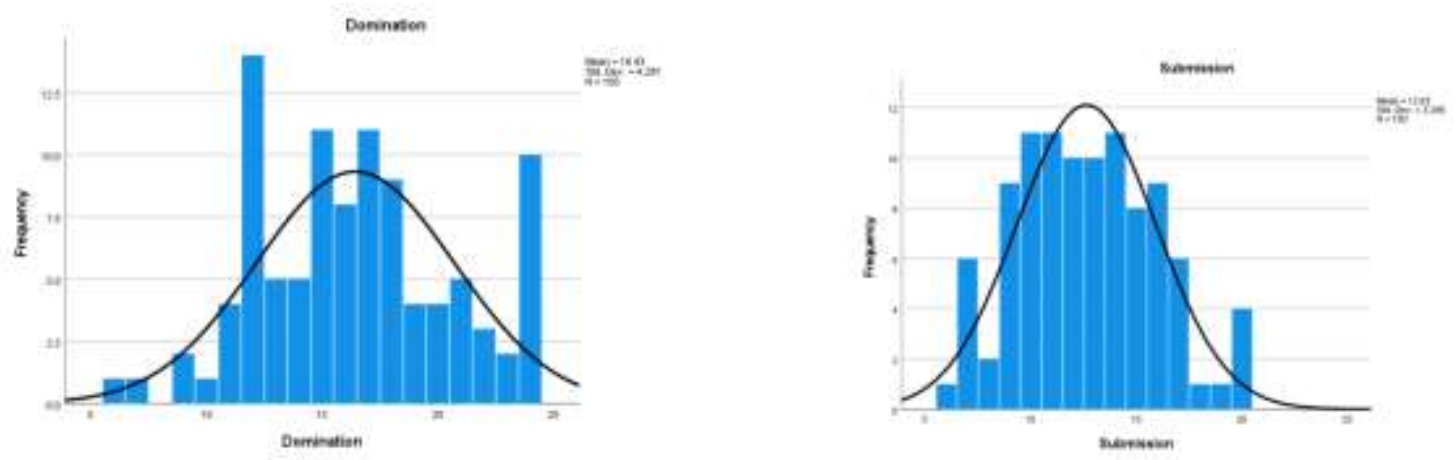

\section{Descriptive Statistics:}

For all of the above histograms, normality analyses gave skewness values close to zero and kurtosis between +1 and -1 . The statistical properties of the data have been presented in the table below. The skewness and kurtosis values suggest that the dataset can be assumed to follow a normal distribution making it suitable for parametric statistical analysis.

Mean, Standard Deviation, skewness, kurtosis of the above data:

\begin{tabular}{|c|c|c|c|c|c|c|c|}
\hline $\mathrm{N}=100$ & Compromise & Avoidance & $\begin{array}{c}\text { Interactional } \\
\text { reactivity }\end{array}$ & Separation & Dominance & Submission & $\begin{array}{c}\text { Gender role } \\
\text { attitude }\end{array}$ \\
\hline Mean & 41.93 & 8.38 & 16.55 & 13.81 & 16.43 & 12.63 & 115.31 \\
\hline Median & 41.00 & 8.00 & 16.00 & 14.00 & 16.00 & 12.50 & 118.50 \\
\hline Mode & 35 & 7 & 15 & 17 & 12 & 10 & 114 \\
\hline SD & 7.429 & 2.228 & 3.669 & 3.329 & 4.281 & 3.296 & 12.830 \\
\hline Skewness & .238 & -.073 & .257 & -.023 & .127 & .217 & -.276 \\
\hline Kurtosis & -.861 & -.652 & -.260 & -.471 & -.542 & -.458 & -.763 \\
\hline
\end{tabular}

- Showing the statistics of gender role conflict and romantic partner conflict:

Correlation between the two variables - 


\begin{tabular}{|c|c|c|c|c|c|c|}
\hline Variables & \multicolumn{6}{|c|}{ Romantic partner conflict } \\
\hline $\begin{array}{c}\text { Gender role } \\
\text { attitude }\end{array}$ & Compromise & Avoidance & $\begin{array}{c}\text { Interactional } \\
\text { reactivity }\end{array}$ & Separation & Dominance & Submission \\
\hline & $-.567^{* *}$ & -.161 & -.147 & -.176 &.$-.223^{* *}$ & 0.50 \\
\cline { 2 - 7 } & $<0.001$ & .109 & .145 & .080 & .026 & .624 \\
\hline
\end{tabular}

**significant at 0.05 level

\section{Observations from correlation analysis results:}

- Objective 1:To study the relationship between gender role attitude and compromise

- Hypothesis 1:There is no significant relationship between gender role attitude and Compromise

- Result: There is a significant relationship between gender role attitude and compromise, with a low negative correlation of -.567 , significant at $\mathrm{p}>0.05$. Thus, the null hypothesis

\begin{tabular}{|c|c|c|c|}
\hline \multicolumn{4}{|c|}{ Correlations } \\
\hline & & Compromise & $\begin{array}{c}\text { Gender role } \\
\text { attitude }\end{array}$ \\
\hline \multirow[t]{3}{*}{ Compromise } & Pearson Correlation & 1 & $-.567^{\pi x}$ \\
\hline & Sig. (2-tailed) & & $<.001$ \\
\hline & $N$ & 100 & 100 \\
\hline \multirow[t]{3}{*}{ Gender role attitude } & Pearson Correlation & $-.567^{x \approx}$ & 1 \\
\hline & Sig. (2-tailed) & $<.001$ & \\
\hline & $\mathrm{N}$ & 100 & 100 \\
\hline
\end{tabular}

$\star \star$. Correlation is significant at the 0.01 level (2-tailed).

is rejected.

- Objective 2: To study the relationship between gender role attitude and avoidance.

- Hypothesis 2: There is no significant relationship between gender role attitude and avoidance.

- Result: There is no significant relationship between gender role attitude and avoidance which indicates that the null hypothesis has been accepted. $(p>0.05)$ 


\begin{tabular}{|c|c|c|c|}
\hline \multicolumn{4}{|c|}{ Correlations } \\
\hline & & Avoldance & $\begin{array}{c}\text { oender role } \\
\text { attitude }\end{array}$ \\
\hline \multirow[t]{3}{*}{ Avoldance } & Pearsin Comretation & $T$ & -.767 \\
\hline & Big. (Z-tatied) & & 109 \\
\hline & $\mathrm{N}$ & 100 & 100 \\
\hline \multirow[t]{3}{*}{ Oender role attutude } & Pearson correlation & -.761 & 1 \\
\hline & sid. (z-talled) & -109 & \\
\hline & N & 100 & 100 \\
\hline
\end{tabular}

- Objective 3: To study the relationship between gender role attitude and interactional reactivity.

- Hypothesis 3: There is no significant relationship between gender role attitude and interactional reactivity.

- Result: There is no significant relationship between gender role conflict and interactional reactivity, indicating acceptance of the null hypothesis $(\mathrm{p}>0.05)$.

\begin{tabular}{|c|c|c|c|}
\hline \multicolumn{4}{|c|}{ Correlations } \\
\hline & & $\begin{array}{c}\text { Interactional } \\
\text { Reactivity }\end{array}$ & $\begin{array}{c}\text { Gender role } \\
\text { attitude }\end{array}$ \\
\hline \multirow[t]{3}{*}{ Interactional Reactivity } & Pearson Correlation & 1 & -.147 \\
\hline & Sig. (2-tailed) & & .145 \\
\hline & $\mathrm{N}$ & 100 & 100 \\
\hline \multirow[t]{3}{*}{ Gender role attitude } & Pearson Correlation & -.147 & 1 \\
\hline & Sig. (2-tailed) & .145 & \\
\hline & $\mathrm{N}$ & 100 & 100 \\
\hline
\end{tabular}

- Objective 4: To study the relationship between gender role attitude and separation.

- Hypothesis 4: There is no significant relationship between gender role attitude and separation.

- Result: There is no significant relationship between gender role conflict and separation, indicating acceptance of the null hypothesis $(\mathrm{p}>0.05)$.

\section{Correlations}

\begin{tabular}{ll|r|r} 
& & Separation & \multicolumn{1}{c}{$\begin{array}{c}\text { Gender role } \\
\text { attitude }\end{array}$} \\
\hline Separation & Pearson Correlation & 1 & -.176 \\
\cline { 2 - 4 } & Sig. (2-tailed) & 100 & .080 \\
\cline { 2 - 4 } Gender role attitude & Pearson Correlation & -.176 & 100 \\
\hline & Sig. (2-tailed) & .080 & 1 \\
\cline { 2 - 4 } & $\mathrm{N}$ & 100 & 100 \\
\hline
\end{tabular}

- Objective 5: To study the relationship between gender role attitude and domination. 
- Hypothesis 5: There is no significant relationship between gender role attitude and domination.

- Result: There is a significant relationship between gender role attitude and domination, with a low negative correlation of -.223 , significant at $\mathrm{p}>0.05$. Thus, the null hypothesis is rejected.

\begin{tabular}{|c|c|c|c|}
\hline \multicolumn{4}{|c|}{ Correlations } \\
\hline & & Domination & $\begin{array}{c}\text { Sender role } \\
\text { attitude }\end{array}$ \\
\hline \multirow[t]{3}{*}{ Domination } & Pearsan Corratatian & 1 & $-.223^{-}$ \\
\hline & sig. (2-tailed) & & 026 \\
\hline & N & 100 & 100 \\
\hline \multirow[t]{3}{*}{ oender role attitude } & Pearson Correlation & $-223^{\circ}$ & 1 \\
\hline & Bid. (z-talled) & $0 \geq 6$ & \\
\hline & $\mathrm{N}$ & 100 & 100 \\
\hline
\end{tabular}

- Objective 6: To study the relationship between gender role attitude and submission

- Hypothesis 6: There is no significant relationship between gender role attitude and submission

- Result: There is no significant relationship between gender role attitude and submission, with a positive correlation of .624 , significant at $\mathrm{p}>0.05$. Thus, the null hypothesis is accepted.

\begin{tabular}{|c|c|c|c|}
\hline \multicolumn{4}{|c|}{ Correlations } \\
\hline & & Submission & $\begin{array}{c}\text { Gender role } \\
\text { attitude }\end{array}$ \\
\hline \multirow[t]{3}{*}{ Submission } & Pearson Correlation & 1 & .050 \\
\hline & Sig. (2-tailed) & & .624 \\
\hline & $\mathbf{N}$ & 100 & 100 \\
\hline \multirow[t]{3}{*}{ Gender role attitude } & Pearson Correlation & .050 & 1 \\
\hline & Sig. (2-tailed) & .624 & \\
\hline & $N$ & 100 & 100 \\
\hline
\end{tabular}

\section{Summary}

The title of the study is "To see the relationship between gender roles attitude and romantic partner conflict among males." The scales used for the study were the Gender role attitude scale and the Romantic partner conflict scale. The obtained data for the study was computed and analyzed with the help of SPSS (Statistical Package for Social Sciences). SPSS software is a popular program for statistical analysis. The result of the study shows that gender role has a 
significant correlation with compromise and domination, whereas, it has no significant relationship with avoidance, interactional reactivity, and submission.

\section{Significant Findings:}

1. There is a significant relationship between gender role attitude and compromise, with a low negative correlation of -.567. This is a strong negative correlation indicating that males exhibiting a compromising and accommodating attitude towards their spouses leads to a decrease in observed romantic partner conflicts. This is at par with intuitive expectations.

2. There is no significant relationship between gender role attitude and avoidance which indicates that the null hypothesis has been accepted.

3. There is no significant relationship between gender role attitude and interactional reactivity.

4. There is no significant relationship between gender role conflict and separation, indicating acceptance of the null hypothesis.

5. There is a significant relationship between gender role attitude and domination, with a low negative correlation of -.223 . The correlation is low and negative. This indicated that dominating behavior on part of the males leads to reduced romantic conflicts. The observed correlation is not too strong, even though the negative correlation behind these two variables seems counterintuitive. Probable reasons may be submissive behavior on the side of the females leading to acceptance of said dominating attitude by the males. The introduction of a much larger number of data points may be useful in fully understanding the dynamics at play in this regard.

6. There is no significant relationship between gender role conflict and submission, indicating acceptance of the null hypothesis.

\section{Implications:}


This research was done to understand the implications of gender role attitude and romantic partner conflict in males. This research only points to whether there is any relationship between the given variables.

\section{Limitations of the study:}

Limitations are influences that the researcher cannot control. They are the shortcomings, conditions, or influences that cannot be controlled by the researcher that place restrictions on the methodology and conclusions.

- Sample size / Sample diversity: For some of the observed correlations, a larger data set would be better in establishing a causal correlation between variables. At present 100 data points were obtained. For a sample of this magnitude, enough diversity of the underlying male population could not be obtained. For example, different age groups (generations) and people from different social and economic backgrounds would react differently to gender bias effects in relationships. The sampling method is convenient sampling, hence the sample is not widely diversified.

- Difficulty in collecting data / Inherent shortcomings in data collection procedure: Data collection was constrained by the collectors' scope, leading to more data points from people of the same age group and economic background. Also for the given sample size, there is always an issue of erroneous fill-out of the initial data collection questionnaire. Such errors are largely canceled out (normalized) for larger datasets.

- Lack of prior research studies on the topic: A literature review is an important part of any research because it helps to identify the scope of works that have been done so far. Literature review findings are used as the foundation for the researcher to be built upon to achieve her research objectives.

- This study uses a self-conducted questionnaire,e which means that the person filling the form can manipulate the data or be influenced by their current mood.

- This research does not analyze scores obtained objectively under observation.

- Since this research was conducted during a global pandemic, the scores obtained can differ if there was no such situation.

\section{Conclusion:}


The study resulted in an insignificant relationship between gender role attitude and domains of romantic partner conflict i.e. interactional reactivity, avoidance, separation, and submission. There is a significant relationship between gender role attitude and compromise, with a low negative correlation of -.567 . There is a significant relationship between gender role attitude and domination, with a low negative correlation of -.223 . The correlation is low and negative.

The introduction of a much larger number of data points may be useful in fully understanding the dynamics at play in this regard.

\section{References}

Bernard J., 1981. "The Good Provider Role: Its Rise and Fall." The American Psychologist 36(1): 1-12.

Barbee J. S. and Axinn W. G., Reviewed, Gender Role Attitudes and Marriage among Young Women, The Sociological Quarterly, Vol. 39, No. 1 (Winter, 1998), pp. 11-31 retrieved from http://www.jstor.org/stable/4121009.

Blee K. M. \& Tickamyer A. R., February 1995, Racial Differences in Men`s Attitudes About Women`s Gender Roles, University of Kentucky.

Canary, D. J., Cunningham, E. M.,\& Cody, M. J. (1988). Goal types, gender, and locus of control in managing interpersonal conflict. Communication Research, 15, 426-446.

Canary, D. J., \& Cupach, W. R. (1988). Relational and episodic characteristics associated with conflict tactics. Journal of Social and Personal Relationships, 5, 305-325. 
Canary, D. J., Cupach, W. R., \& Messman, S. J. (1995). Relationship conflict: Conflict in parentchild, friendship, and romantic relationships. Thousand Oaks, CA: Sage.

Canary, D. J., \& Spitzburg, B.H. (1989).A model of the perceived competence of conflict strategies. Human Communication Research.

Canary, D. J., \& Spitzberg, B. H. (1990). Attribution biases and associations between conflict strategies and competence outcomes. Communication Monographs.

Catania, J. A. (1998). Dyadic Sexual Communication Scale. In C. M. Davis, W. L. Yarber, R. Bauserman, G. Schreer, \& S. L. Davis (Eds.), Handbook of sexuality-related measures. Thousand Oaks, CA: Sage.

Caughlin, J. P.,\& Vangelisti, A. L. (2000). An individual difference explanation of why married couples engage in the demand/withdrawal pattern of conflict. Journal of Social and Personal Relationships,

Christensen, A., \& Shenk, J. L. (1991). Communication, conflict, and psychological distance in A non-distressed, clinic, and divorcing couples. Journal of Consulting and Clinical Psychology,

Christensen,A.,\& Walczynski,P.T. (1997). Conflict and satisfaction in couples. In R. J. Sternberg,

\& M. Hojjat (Eds.), Satisfaction in close relationships. New York: Guilford.

Cramer, D. (2004). Emotional support, conflict, depression, and relationship satisfaction in a romantic partner. The Journal of Psychology.

Cupach, W. R. (2000). Advancing understanding about relational conflict. Journal of Social and Personal Relationships.

Cupach, W. R., \& Comstock, J. (1990). Satisfaction with sexual communication in marriage. Journal of Social and Personal Relationships. 
David W. Johnston, Stefanie Schure, Michael A. Shields, August 2012, Maternal Gender Role Attitudes, Human Capital Investment, and Labour Supply of Sons and Daughters Version: 3rd, Melbourne, Australia.

Frei, J. R., \& Shaver, P. R. (2002). Respect in close relationships: Prototype definition, selfreport assessment, and initial correlates. Personal Relationships.

Genset partner organization, FORTH/IACM, February 2011, Gender Stereotypes and Gender Attitudes in the Assessment of Women's Work

Gottman, J. M. (1993). The roles of conflict engagement, escalation, and avoidance in marital interaction: A longitudinal view of five types of couples. Journal of Consulting and Clinical Psychology,

Jamie Michelle Lewis, The Ohio State University, June 2005, Sex Differences in Gender Role Attitudes,

Kathleen G,.1985, Hard Choices: How Women Decide about Work, Career, and Motherhood. Los Angeles: University of California Press.

Morgan S. P., and Linda J. Waite. 1987. "Parenthood and the Attitudes of Young Adults. "American Sociological Review 52:541-547.

Riley, Sarah C.E. 2003. "The Management of the Traditional Male Role: a discourse analysis of the constructions and functions of provision.” Journal of Gender Studies 12(2): 99-113. 